\title{
Estimate of the contraction rate of central Japan through the deformation of the Philippine Sea slab
}

\author{
Yukitoshi Fukahata
}

\begin{abstract}
The Philippine Sea (PHS) slab is severely deformed beneath central Japan, but it is subject to little deformation before the subduction along the Nankai Trough. Thus, it is considered that the currently observed deformation of the PHS slab has been formed only after the subduction along the Nankai Trough. This study estimates the contraction rate of the PHS slab along segments roughly parallel to the Nankai Trough, assuming that the configuration of the PHS slab is stationary in time in the coordinate system fixed to the overriding plate. Results show that the contraction rate is small beneath most parts of Shikoku ( $\leq 0.3 \mathrm{~mm} /$ year) and the offshore fore-arc ( $\leq 0.6 \mathrm{~mm} /$ year), while it increases from the Pacific coastal region (3-6 mm/year) to the inland region (approximately $20 \mathrm{~mm} /$ year) beneath central Japan. Considering various error sources, the strain rate is estimated to be about $4-7 \times 10^{-8} /$ year beneath the inland region of central Japan, although it could be reduced by about 20\% if the PHS slab has a tear beneath the Kii Strait. Due to the geographical concordance of the deformation between the PHS slab and the upper crust above the slab, the contraction rate of the PHS slab could be used as a proxy to provide an independent estimate of the crustal deformation rate of central Japan over the long term, which is slower than the geodetic estimate while faster than the geologic one.
\end{abstract}

Keywords: Philippine Sea slab, Central Japan, Contraction rate, Strain rate

\section{Introduction}

Geodetic data (Hashimoto 1990; Sagiya et al. 2000; Heki and Miyazaki 2001), seismological data (Townend and Zoback 2006; Terakawa and Matsu'ura 2010), and geological and geomorphological data (Huzita 1980; Research Group for Active Faults of Japan 1991) have consistently shown that most parts of the Japanese islands are currently situated under an east-west (E-W) compression stress field. However, it is not easy to quantitatively estimate the contraction rate of the Japanese islands over the long term, although this parameter is fundamental to understand the tectonics of Japan.

GNSS (Global Navigation Satellite System) data provide accurate estimates of the $\mathrm{E}-\mathrm{W}$ contraction rate, but the observation period is less than a few decades (e.g., Sagiya 2004). Traditional triangulation and trilateration data cover more than a century, though they are not as accurate as GNSS data. However, it is still unclear

Correspondence: fukahata@rcep.dpri.kyoto-u.ac.jp

Disaster Prevention Research Institute, Kyoto University, Gokaho, Uji, Kyoto 611-0011, Japan

(c) The Author(s). 2019 Open Access This article is distributed under the terms of the Creative Commons Attribution 4.0 International License (http://creativecommons.org/licenses/by/4.0/), which permits unrestricted use, distribution, and reproduction in any medium, provided you give appropriate credit to the original author(s) and the source, provide a link to the Creative Commons license, and indicate if changes were made. whether the observed deformation rates can be extrapolated to a geological time scale. For example, large E-W extension has been observed in Honshu island after the 2011 Tohoku-Oki earthquake (e.g., Ozawa et al. 2012). Therefore, the geodetically observed E-W contraction rates before the Tohoku-Oki earthquake are likely overestimated.

From seismic moment release rates due to historical large inland earthquakes, Wesnousky et al. (1982) estimated the E-W contraction rate of Honshu and Shikoku islands for the last 400 years. However, 400 years may still be too short to accurately estimate the contraction rates considering that the recurrence intervals of large inland earthquakes are much longer than several hundred years, which might be even longer than thousands of years. It is also possible to estimate the contraction rate from slip rates on active faults (Wesnousky et al. 1982; Kaizuka and Imaizumi 1984). However, large inland earthquakes have often happened on faults that were previously not identified as active faults, as in the cases of the 2000 Western Tottori earthquake (Asano and Hasegawa 2004)

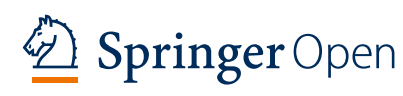


and the 2008 Iwate-Miyagi Nairiku earthquake (Takada et al. 2009; Toda et al. 2010). In addition, the effect of inelastic deformation, such as folding, was not taken into account in their estimates. Thus, the estimated contraction rates could be significantly underestimated. In northeastern Japan, an attempt was made to estimate horizontal shortening ratios from geological cross sections (Sato 1989), but the method cannot be applied to central and western Japan because strike-slip faults are dominant rather than reverse faults.

By the way, slabs usually descend into the mantle with minimal deformation, as indicated by iso-depth contours that are nearly parallel to the trench in most subduction zones (e.g., Hayes et al. 2012). In fact, the iso-depth contours in and around Japan are nearly parallel to the trenches along the Kuril, northeastern Japan, Izu-Bonin, and Ryukyu arcs (e.g., Hashimoto et al. 2004; Nakajima et al. 2009; Hasegawa et al. 2010). With respect to elastic energy, it is also reasonable that slabs should undergo minimal deformation, because slabs are more or less elastic at depth.

Among many slabs of all over the world, however, the Philippine Sea (PHS) slab is an exception. The complicated configuration of the PHS slab beneath central Japan (Fig. 1; Hashimoto et al. 2004) suggests that this portion of the slab has experienced significant deformation. In some subduction zones, such as in southern Mexico (e.g., Pardo and Suárez 1995) and Peru (e.g., Gutscher et al. 2000), the dip angle of the slabs does not increase monotonously but flattens at intermediate depths. However, a slab that is subject to large horizontal deformation is very rare. The reason for the horizontal deformation of the PHS slab is unknown, but the E-W compression applied to the Japanese islands is a likely cause of it, because large $\mathrm{E}-\mathrm{W}$ contraction is needed to realize the present configuration of the PHS slab.

As shown in Fig. 1, the PHS slab severely deforms beneath central Japan, while there is much less deformation beneath western Japan, where the iso-depth contours are subparallel to the Nankai Trough (in this study, the boundary between central Japan and western Japan is taken along the Kii strait and its northern extension; Fig. 1). Such characteristics correspond well to crustal deformation inferred from geological, seismological, and geodetic data; the density of active faults (Research group for active faults of Japan 1991) and the number of historical large earthquakes (Utsu 1990, 2002, 2004, the later updates are added by the International Institute of Seismology and Earthquake Engineering; Matsu'ura 2017) are much larger in central Japan than in western Japan (Fig. 1), and geodetically observed E-W contraction rates are also significantly faster in central Japan (Sagiya et al. 2000). We also observe that the deformation of the PHS slab is smaller beneath the Pacific coastal region than beneath the inland region of central Japan (Fig. 1). This feature is also consistent with the crustal deformation inferred from geological and seismological data.

If the crustal deformation is well correlated with the deformation of the slab beneath the crust, it is possible to quantitatively estimate the contraction rate of the crust using that of the slab. The advantage of this method lies in the simplicity of the initial configuration of the slab. Continental crusts generally have a very long history, and it is thus difficult to extract deformation information that occurred only in the recent few million years. On the other hand, oceanic plates experience almost no horizontal deformation prior to subduction. Therefore, we can consider that the currently observed deformation of the PHS slab has been formed only after subduction along the Nankai Trough.

In the following of this paper, the configuration of the PHS slab and the convergence rate between the PHS plate and the Honshu arc are first reviewed, and the contraction rate of the PHS slab is then estimated. As mentioned above, the estimated contraction rate could be used as a proxy for the contraction rate of central and western Japan.

\section{Configuration of the Philippine Sea slab}

Estimating the configuration of the upper surface of the subducting slab beneath central and western Japan has been more difficult than in other areas of Japan (e.g., Utsu 1974), because comparatively fewer interplate and intraslab earthquakes have occurred in these areas and the PHS slab has a complicated geometry. However, slab configuration models have been proposed by many researchers in the past few decades (e.g., Mizoue et al. 1983; Nakamura et al. 1997; Ishikawa 2001). From the hypocenter distribution of earthquakes, Hashimoto et al. (2004) constructed a 3-D plate interface model in and around Japan (Figs. 1 and 2a), using a technique of Bayes inversion with a smoothness constraint (Yabuki and Matsu'ura 1992); the model is called the CAMP (Crustal Activity Modeling Program) model, and it expresses the plate configuration as a superposition of a finite number of smooth basis functions. From receiver function analysis, Shiomi et al. (2008) and Ueno et al. (2008) depicted the configuration of the oceanic Moho within the PHS slab beneath central and western Japan. From the seismic velocity structure obtained by double-difference tomography, Hirose et al. $(2007,2008$ a) proposed a configuration model of the PHS slab (Fig. 3a), also referring to results of seismic reflection and refraction surveys for shallower regions (Baba et al. 2002) and another tomographic study for deeper regions (Nakajima and Hasegawa 2007); this plate configuration model is referred to as the Hirose model in this study. 


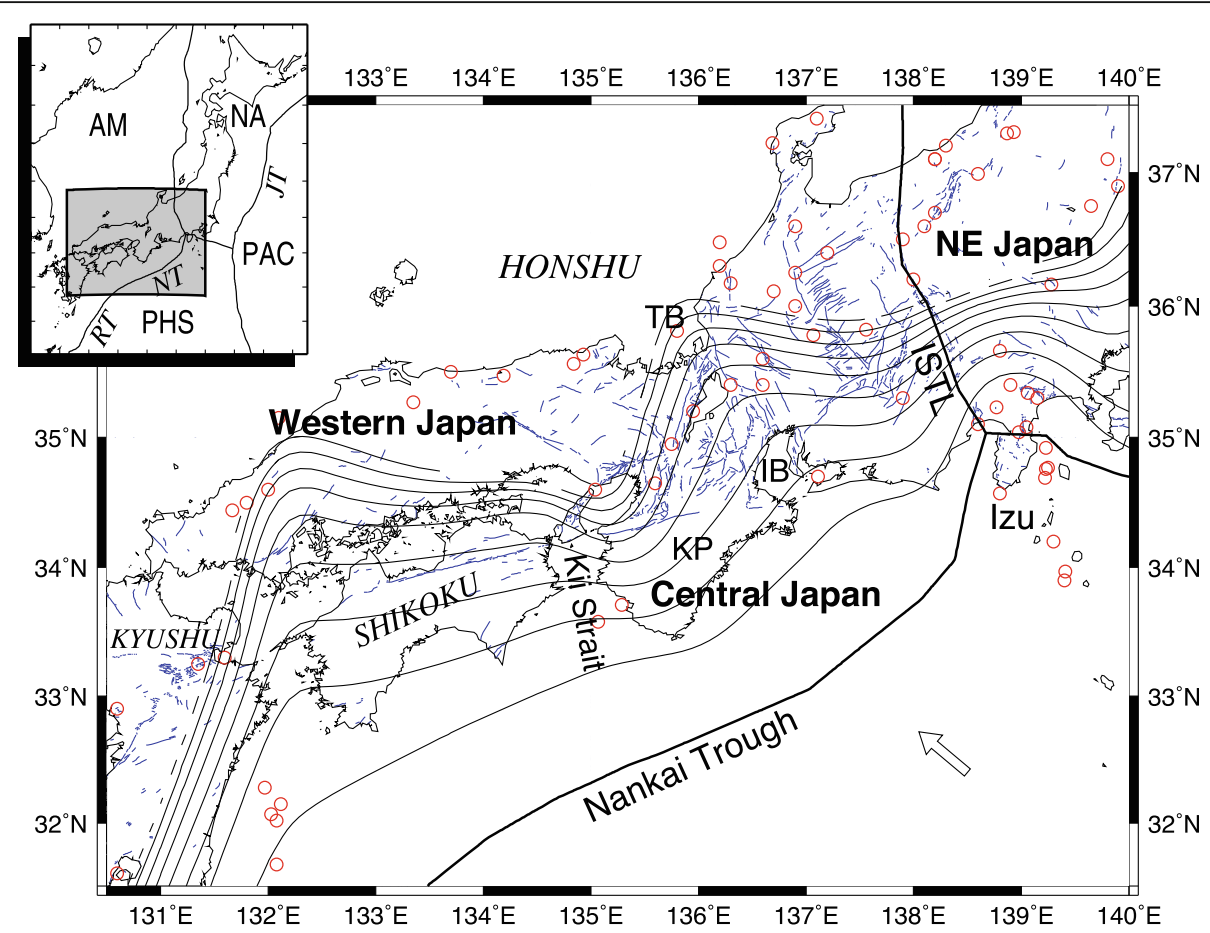

Fig. 1 Location map of central and western Japan. Thick solid lines represent plate boundaries after Bird (2003). Red open circles are epicenters of very shallow $(\leq 20 \mathrm{~km})$, historical $(1586 \leq$ year $\leq 2013)$, and large $(M \geq 6.5)$ earthquakes from the Catalog of Damaging Earthquakes in the World (Utsu 1990, 2002, 2004, the later updates are added by the International Institute of Seismology and Earthquake Engineering) with additional depth data for historical earthquakes (Matsu'ura 2017). Thin blue lines are active faults on land (Research Group for Active Faults of Japan 1991). Contour lines of the PHS slab of the CAMP model (Hashimoto et al. 2004) are also shown every $10 \mathrm{~km}$ by thin solid lines. The following acronyms are used: ISTL, Itoigawa-Shizuoka tectonic line; KP, Kii Peninsula; IB, Ise Bay; TB, Tsuruga Bay; NE, northeastern; AM, Amurian Plate; PHS, Philippine Sea Plate; PAC, Pacific Plate; NA, North American Plate; JT, Japan Trench; NT; Nankai Trough; RT, Ryukyu Trench

Although the details of these proposed plate configuration models are different, they consistently show that the PHS slab is heavily deformed with a folded structure. The topography of the PHS slab has a valley beneath the western Kii Peninsula (KP in Fig. 1), where the dip angle of the slab is steeper than the adjacent areas, and has a ridge beneath the region between the Ise Bay and the Tsuruga Bay, where the dip angle is shallower. On the other hand, the deformation of the PHS slab is limited beneath Shikoku and the offshore fore-arc (i.e., between the Nankai Trough and the Pacific coast line), where the contours of the PHS slab are subparallel to the trench. We can also notice that the deformation of the PHS slab beneath central Japan increases from south to north.

Some studies have proposed the existence of a tear beneath the Kii Strait, on the basis of seismicity data (Ishikawa 2001; Cummins et al. 2002), a receiver function analysis (Ueno et al. 2008), and the distribution of deep tremors (Ide et al. 2010). The location of this hypothetical tear roughly corresponds to the extinct spreading ridge of a marginal basin (Shikoku Basin) in the PHS plate (Okino 1994). Because the extinct spreading ridge is considered mechanically weak, Ide et al. (2010) claimed that the tear had been formed by an abrupt change in subduction direction a few million years ago, although it is still unclear whether the tear exists or not.

The strike of the Nankai Trough sharply bends to the north around the Izu Peninsula (Fig. 1). This peculiar form of the plate boundary is ascribed to the collision of the Izu arc with the Honshu arc (Sugimura 1972; Matsuda 1978); the continental crust of the Izu arc on the PHS plate has intruded into the Honshu arc. A similar indentation structure is observed for the collision between the Indian continent and the Eurasian plate (Tapponnier and Molnar 1976; Takada and Matsu'ura 2004). Such an indentation structure develops with progressing convergent plate motion, because buoyant continental crust, which cannot subduct deep into the mantle, continues to move on the Earth's surface following the plate motion. Thus, the geometry of the plate boundary around the Izu Peninsula has rapidly changed on a geological time scale. The degree of indentation of the Izu block would be smaller in the recent past, for example, Imanaga (1999) considered the Izu block had no indentation at $2 \mathrm{Ma}$ in the study of depositional sequences, although the situation may be more complicated because multiple collisions have occurred in this area (e.g., Amano 1991). 


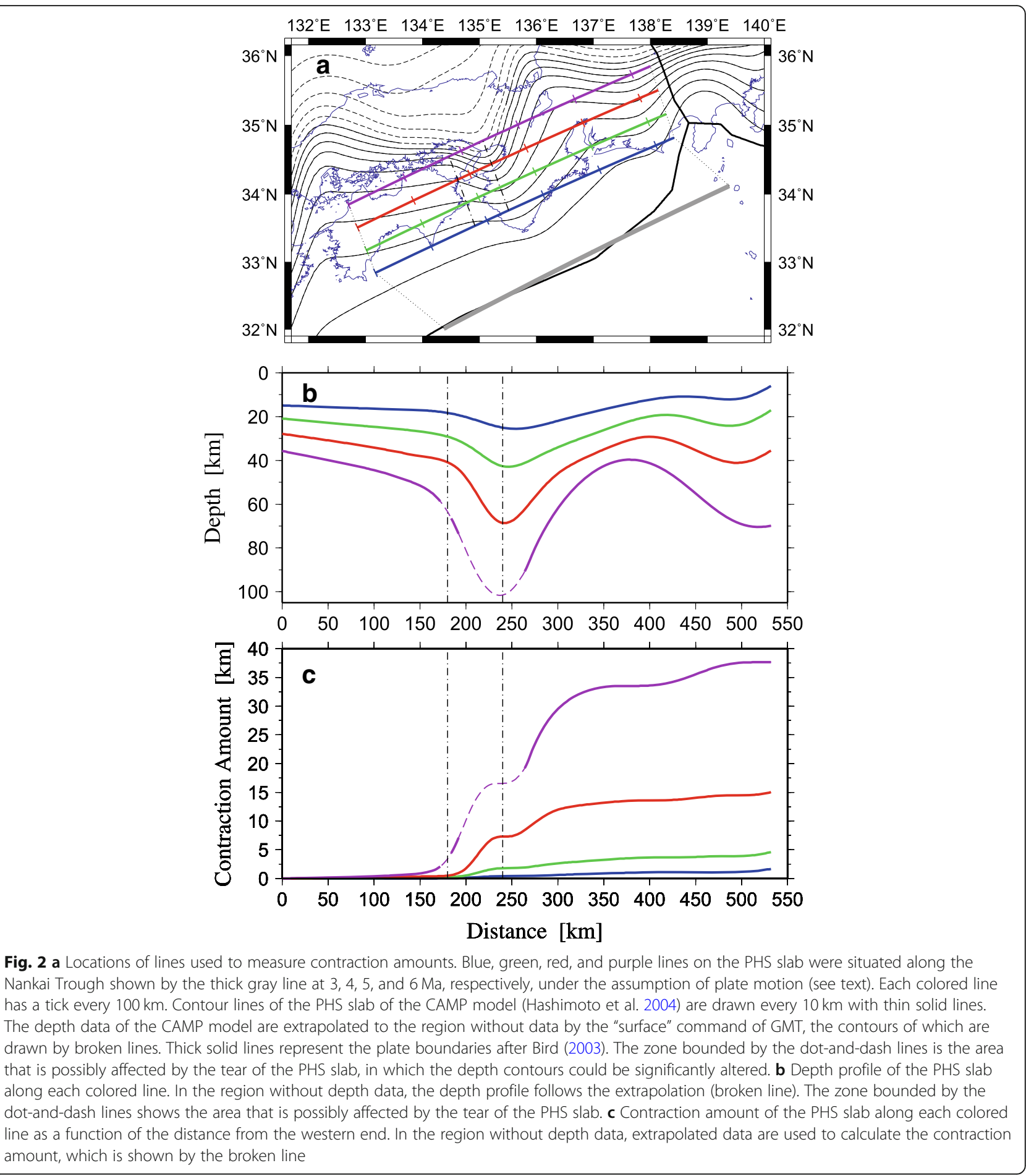

\section{Plate convergence between the Philippine Sea plate and the Honshu arc}

The PHS slab moves relative to the Honshu arc. Therefore, prior to estimating the contraction rate of the PHS slab, it is necessary to consider this relative motion. However, it has been difficult to estimate the motion of the PHS plate, because it has neither hotspot tracks nor long spreading ridges.

Using slip vectors of large interplate earthquakes along the PHS plate boundary and the constraints of the motion with the Pacific and Caroline plates, Seno et al. (1993) estimated the motion of the PHS plate relative to 


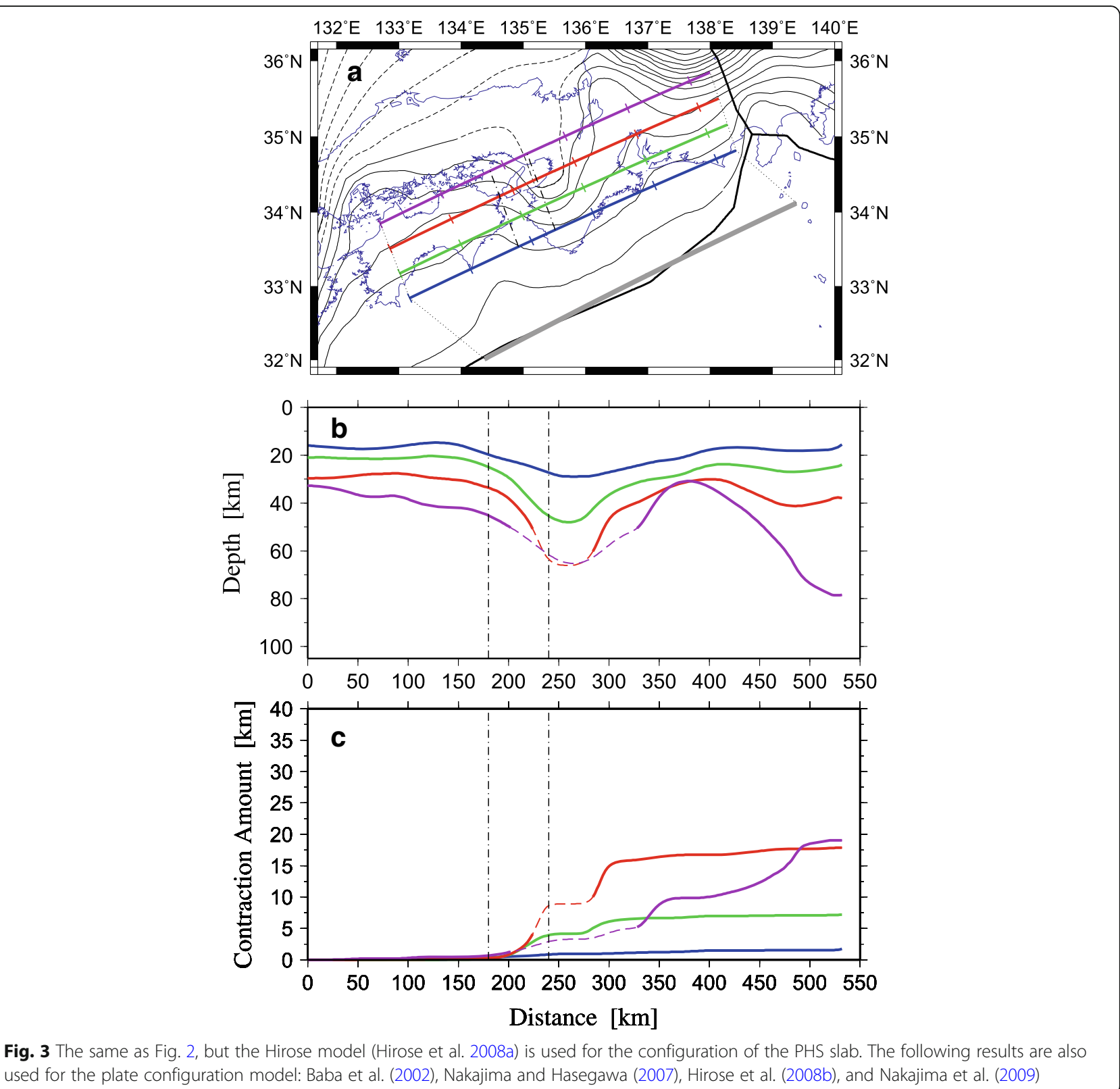

the Eurasian plate as 40-45 mm/year toward NW (about $\left.\mathrm{N} 50^{\circ} \mathrm{W}\right)$. However, western Japan is considered to belong to the Amurian plate, not to the Eurasian plate. From GNSS data, Heki et al. (1999) showed that the Amurian plate moves eastward relative to the Eurasian plate at a rate of about $10 \mathrm{~mm} /$ year. On the other hand, Heki and Miyazaki (2001) showed that the Amurian plate converges to the North American (NA) plate in E-W direction as fast as $20 \mathrm{~mm} /$ year, which means that the NA plate moves westward at a rate of about $10 \mathrm{~mm} /$ year relative to the Eurasian plate. Hence, if central Japan converges to the NA plate at a rate of about $10 \mathrm{~mm} /$ year, then there is almost no relative motion between central Japan and the Eurasian plate. It is thus considered that the estimate of Seno et al. (1993) may be feasible as a convergence rate between the PHS plate and central Japan, even though the Amurian plate is not taken into account in their model.

Using GNSS data, Sella et al. (2002) determined the relative plate motion between the PHS plate and Amurian plate to be $60-70 \mathrm{~mm} /$ year toward WNW. This estimate is significantly faster and more westerly than that of Seno et al. (1993), even if the motion of the Amurian plate is considered. Hashima et al. (2016) recently pointed out that Sella's model does not match the earthquake slip vector along the PHS plate boundary. Because there are 
few islands on the stable part of the PHS plate, short-term fluctuations may be included in the observed GNSS data. Therefore, the plate motion model of Seno et al. (1993) is used as the current velocity in the following analysis.

At present, the PHS plate subducts to the NW along the Nankai Trough. However, it has been widely considered that the PHS plate moved to the NNW in the late Miocene, from surface geology and paleomagnetic data (Matsuda 1978; Seno and Maruyama 1984; Takahashi 2006). Striations of tremor activity beneath Shikoku also suggest that the PHS plate moved toward the NNW in the past (Ide 2010). On the other hand, there is disagreement on the timing of the plate motion change, which ranges from 10 to $4 \mathrm{Ma}$ (Seno and Maruyama 1984) to $1.0-0.5 \mathrm{Ma}$ (Hashima et al. 2016). Nevertheless, it would be reasonable to consider that the change occurred between 4 and $2 \mathrm{Ma}$ (Ide et al. 2010), because the present mode of tectonics of the Japanese arc system began at around that time (e.g., Chinzei and Koaze 1995; Taira 2001; Doke et al. 2012; Otsubo and Miyakawa 2016). In the following analysis, it is assumed that the change in the PHS plate motion from NNW to NW occurred at 3 $\mathrm{Ma}$; this corresponds to the timing of the plate motion change adopted by Takahashi $(2006,2017)$, which is based on the timing of the Kurotaki Unconformity.

The convergence rate before the change in motion has also not been clarified yet. For example, Seno and Maruyama (1984) estimated it as $60 \mathrm{~mm} /$ year based on the paleogeographic reconstruction of the PHS plate, while Takahashi (2006) estimated it as about $30 \mathrm{~mm} /$ year based on the assumption that the tip of the PHS slab that began to subduct at $15 \mathrm{Ma}$ now reaches beneath the volcanic front in southwestern Japan. In short, there are not enough available data to constrain the convergence rate. Therefore, for simplicity, it is assumed in the following analysis that the plate convergence rate has not significantly changed in the recent several million years.

\section{Methods and results}

In this section, contraction rates of the PHS slab are estimated from the slab configuration models (the CAMP model (Fig. 2a) and the Hirose model (Fig. 3a)). First, depth profiles of the PHS slab along segments roughly parallel to the Nankai trough are taken (Figs. 2b and $3 \mathrm{~b})$. Once the depth profiles are obtained, we can estimate the contraction amount of them (Figs. 2c and $3 c)$, because the depth profiles are considered to be flat prior to subduction. Figure 4 schematically shows the method to measure the contraction amount of slab from its depth profile. As for the conversion from contraction amount to contraction rate, the plate convergence rates that were reviewed in the previous section are used.

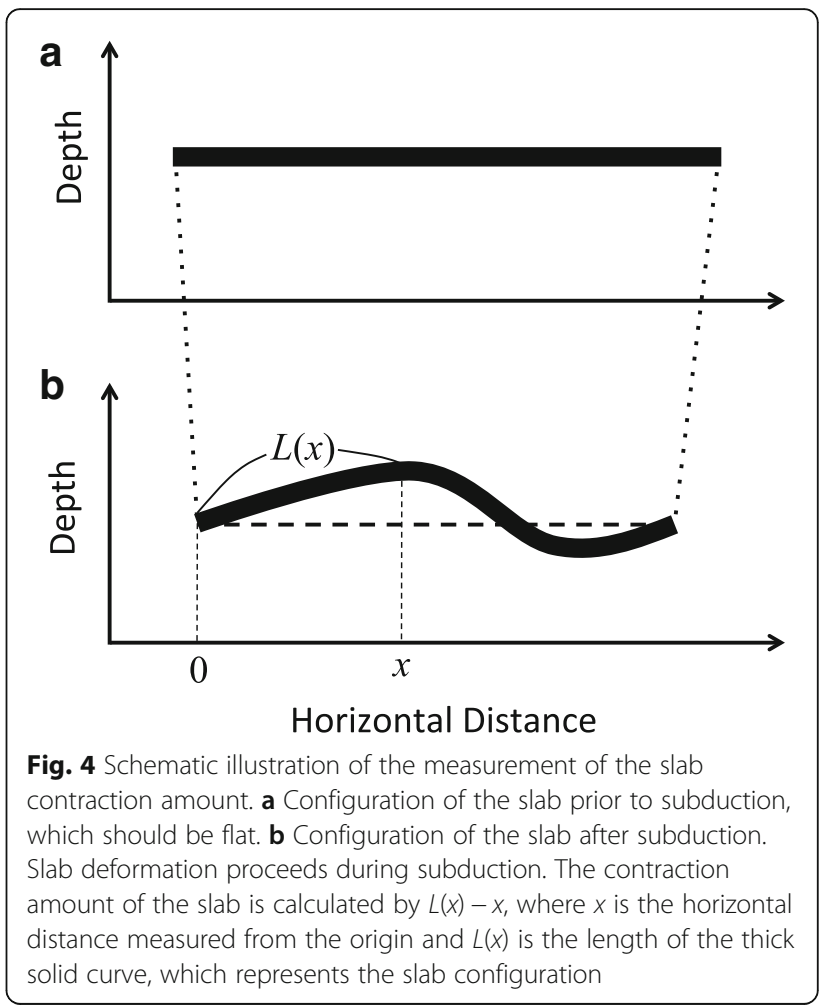

\section{Depth profiles of the PHS slab}

We only know the present configuration of the PHS slab. In order to estimate its contraction rate, however, we also need to know its past configuration, which has not been clarified yet. Therefore, in this study, spatial change of the contraction amount of the PHS slab is regarded as the temporal change of it. In other words, the configuration of the PHS slab is assumed to be stationary in time on the coordinate system fixed to the overriding plate (the Honshu arc), except for the region around the Izu Peninsula.

I roughly take a segment of the PHS slab along the Nankai Trough as shown by the thick gray line in Fig. 2a, where the effect of the indentation of the trench axis due to the northward motion of the Izu block is retrieved as discussed in the "Configuration of the Philippine Sea slab" section. If the PHS slab subducts without significant deformation, this segment reaches the locations indicated by the blue, green, red, and purple lines for the recent 3,4 , 5 , and $6 \mathrm{Ma}$, respectively. In other words, the segments of the colored lines were situated along the Nankai Trough shown by the thick gray line before 3 to $6 \mathrm{Ma}$. Here, as mentioned above, the relative motion between the PHS plate and Honshu arc is assumed to follow the estimate by Seno et al. (1993) $(40-45 \mathrm{~mm} /$ year toward about $\mathrm{N}$ $50^{\circ} \mathrm{W}$ ) in the recent $3 \mathrm{Ma}$ and to have been $40 \mathrm{~mm} /$ year toward $\mathrm{N} 20^{\circ} \mathrm{W}$ before $3 \mathrm{Ma}$. In drawing the colored lines in Fig. 2a, the dip of the slab is assumed to be zero for 
simplicity, because the distance can be only a few percent shorter, even if the effect of the slab dip is taken into account. As shown in Fig. 2a, the eastern end of the colored lines roughly corresponds to the Itoigawa-Shizuoka tectonic line (ISTL), which is taken as the boundary between the Amurian and NA plates. The western end of them is located in western Shikoku; the PHS slab sharply bends to the west of it, reflecting the change of the strike from the Nankai Trough to the Ryukyu Trench. It is also evident that the part of the PHS slab that subducted in the recent $3 \mathrm{Ma}$ is mostly situated beneath the offshore fore-arc.

Contour lines on the upper surface of the PHS slab in the CAMP model are also shown in Fig. 2a by solid lines. However, the purple line passes through a region where the CAMP model does not provide depth data because of the smaller number of earthquakes. Therefore, with the "surface" command of General Mapping Tools (GMT; Wessel and Smith 1998), the CAMP model depth data are extrapolated for this region, as shown by the broken lines. Figure 3a shows the contours of the PHS slab of the Hirose model, in which the results of Hirose et al. (2008b) and Nakajima et al. (2009) are added to the compilation of Hirose et al. (2007, 2008a). On the homepage of the Hirose Model (Hirose 2018), contour line data are provided every $10 \mathrm{~km}$. Therefore, to obtain the PHS slab depth at arbitrary points, interpolation as well as extrapolation is conducted using the "surface" command of GMT. Contours obtained by the extrapolation are drawn by the broken lines.

The depth profile of the PHS slab along each of the colored lines is shown in Figs. $2 \mathrm{~b}$ and $3 \mathrm{~b}$ for the CAMP and Hirose models, respectively, where the distance (horizontal axis) is measured from the western end. The folding structure with a syncline beneath the western Kii Peninsula and an anticline beneath the Ise Bay is evident in the depth profiles. As previously mentioned, depth data are extrapolated for some portions of the colored lines, where the depth profiles are shown by broken lines.

\section{Contraction rate of the PHS slab}

Because the depth profiles should be flat prior to subduction, it is possible to estimate the amount of PHS slab contraction using the depth profiles (Figs. $2 \mathrm{~b}$ and $3 \mathrm{~b}$ ). A schematic illustration to estimate the contraction amount is shown in Fig. 4. Specifically, the difference between the length measured along the depth profile curve, $L(x)$, and the distance corresponding to the horizontal axis, $x$, provides the contraction amount. Figures $2 \mathrm{c}$ and $3 \mathrm{c}$ show the contraction amount along each colored line as a function of the distance from the western end. It can be seen from these diagrams that almost no contraction has occurred beneath Shikoku and the offshore fore-arc, but contraction has steadily proceeded beneath central Japan.
The contraction amount of each colored line is summarized in Table 1; the line numbers $3,4,5$, and 6 correspond to the blue, green, red, and purple lines, respectively. As mentioned above, these colored lines were situated along the Nankai Trough at 3, 4, 5, and $6 \mathrm{Ma}$, respectively. In Table 1, the boundary between Shikoku and central Japan is more specifically taken at $180 \mathrm{~km}$ from the western end of the profile. The contraction amount for the purple line of the Hirose model is smaller than that of the green and red lines beneath the Kii Peninsula, and so the amount is apparently unreliable. The extrapolation scheme of the data might not work well for the Hirose model. Apart from that, the two models (CAMP and Hirose) provide similar contraction amounts for each colored line.

The spatial change in the contraction amounts can be obtained by taking the difference between the contraction amounts of two adjacent colored lines. As mentioned above, the spatial difference of each colored line basically corresponds to the difference of $1 \mathrm{Myr}$ in the subduction of the PHS slab. Therefore, the contraction rates of the PHS slab for the recent $1 \mathrm{Myr}$ can be estimated from the spatial change in the contraction amounts. The results are shown in Table 2. For example, the contraction rate of the zone " $4-5$ " in Table 2, which represents the contraction rate for the recent $1 \mathrm{Myr}$ in the area between the green and red lines beneath central Japan, is $10.1 \mathrm{~mm}$ /year in the CAMP model and $10.6 \mathrm{~mm} /$ year in the Hirose model. The contraction rate of central Japan increases from the coastal region (approximately $3-6 \mathrm{~mm} /$ year) to the inland region (approximately $20 \mathrm{~mm} /$ year). On the other hand, the contraction rates beneath Shikoku are quite small $(\leq 0.3 \mathrm{~mm} /$ year $)$, except for the northernmost part (approximately $3 \mathrm{~mm} /$ year). The contraction rate beneath the offshore fore-arc is also small $(\leq 0.6 \mathrm{~mm} /$ year in the recent $3 \mathrm{Myr}$ ), so these rates are omitted from

Table 1 Contraction amount of the PHS slab along each segment. The line numbers, 3, 4, 5, and 6 correspond to the blue, green, red, and purples lines, respectively, for the CAMP model (a) and the Hirose model (b). The unit of the contraction amount is kilometer. The contraction amount obtained for line 6 of the Hirose model is unreliable

\begin{tabular}{|c|c|c|c|c|c|}
\hline & Line & $\begin{array}{l}\text { Total } \\
(0-530 \text { km) }\end{array}$ & $\begin{array}{l}\text { Shikoku } \\
(0-180 \text { km) }\end{array}$ & $\begin{array}{l}\text { Central Japan } \\
(180-530 \mathrm{~km})\end{array}$ & $\begin{array}{l}\text { Possible tear zon } \\
(180-240 \mathrm{~km})\end{array}$ \\
\hline \multirow[t]{4}{*}{ (a) } & 3 & 1.7 & 0.04 & 1.6 & 0.4 \\
\hline & 4 & 4.6 & 0.2 & 4.4 & 1.6 \\
\hline & 5 & 15.0 & 0.5 & 14.5 & 6.8 \\
\hline & 6 & 37.6 & 3.4 & 34.2 & 13.1 \\
\hline \multirow[t]{4}{*}{ (b) } & 3 & 1.7 & 0.4 & 1.4 & 0.5 \\
\hline & 4 & 7.2 & 0.3 & 6.9 & 3.7 \\
\hline & 5 & 17.9 & 0.3 & 17.6 & 8.3 \\
\hline & 6 & 19.0 & 0.7 & 18.4 & 2.2 \\
\hline
\end{tabular}


Table 2 Contraction rate and strain rate of the PHS slab beneath central Japan. The zone numbers represent the area bounded by the colored lines (e.g., the zone 4-5 is the area bounded by the green and red lines). The numbers in parentheses represent the cases with a tear beneath the Kii strait. (a) CAMP model, (b) Hirose model

\begin{tabular}{llll}
\hline & Zone & Contraction rate $(\mathrm{mm} /$ year $)$ & Strain rate $\left(\times 10^{-8} /\right.$ year $)$ \\
\hline (a) & $3-4$ & $2.8(1.6)$ & $0.8(0.5)$ \\
& $4-5$ & $10.1(4.9)$ & $2.9(1.7)$ \\
& $5-6$ & $19.7(13.4)$ & $5.6(4.6)$ \\
(b) & $3-4$ & $5.6(2.4)$ & $1.6(0.8)$ \\
& $4-5$ & $10.6(6.0)$ & $3.0(2.1)$ \\
\hline
\end{tabular}

Table 2, for simplicity. Dividing the contraction rate by $350 \mathrm{~km}(=530 \mathrm{~km}-180 \mathrm{~km})$, we can obtain the strain rate of the PHS slab deformation beneath central Japan (Table 2), which is $0.8 \sim 1.6 \times 10^{-8} /$ year beneath the Pacific coastal region and reaches $5.6 \times 10^{-8} /$ year beneath the inland region. On the other hand, the strain rate beneath Shikoku and the offshore fore-arc is small $\left(\leq 0.2 \times 10^{-8} /\right.$ year) except for the northernmost part of Shikoku $(1.6 \times$ $10^{-8}$ /year).

If the PHS slab has a tear beneath the Kii Strait, as claimed by Ide et al. (2010), then the estimated contraction amount would be significantly affected, because the contraction amount beneath the Kii strait and the westernmost part of the Kii Peninsula would possibly decrease to zero. In order to quantitatively take this effect into account, the contraction amount between 180 and $240 \mathrm{~km}$ in the distance of the horizontal axis of Figs. 2 and 3 is also shown in the right edge column of Table 1 . This would give the upper limit of the effect of the tear on the contraction amount. If the contraction amount between $180 \mathrm{~km}$ and $240 \mathrm{~km}$ decrease to zero, the contraction rate and the strain rate of central Japan change to the values shown in the parentheses of Table 2, where the strain rates are obtained by dividing by $290 \mathrm{~km}$ instead of $350 \mathrm{~km}$ because the length of large deformation also decreases. As shown in Table 2, a tear in the PHS slab beneath the Kii strait could reduce the strain rate by about $20-40 \%$, leading to the values of $0.5-0.8 \times 10^{-8} /$ year beneath the Pacific coastal region and $4.6 \times 10^{-8} /$ year in the inland region of central Japan.

\section{Discussion}

In the previous section, contraction and strain rates of the PHS slab were estimated, but these estimations contain non-negligible uncertainties.

The largest uncertainty is related to the configuration of the plate models. The CAMP and Hirose models are basically consistent in terms of the contraction amounts (Table 1), but they differ up to a few kilometers, which results in the difference of a few $\mathrm{mm} /$ year in the contraction rate (Table 2). Other plate configuration models may provide different contraction amounts. The biggest difficulty is the possibility of tear, which could reduce the strain rate by $20-40 \%$, as previously mentioned.

In this study, differences in the contraction amounts between colored lines were calculated to estimate the contraction rates for the most recent 1 Myr. The spatial differences in the locations of the colored lines in Figs. 2a and $3 \mathrm{a}$ are based on the assumed plate motion before $3 \mathrm{Ma}$. Therefore, it could be considered more appropriate to use differences in the contraction amounts of segments that are not defined by past plate motion but by present plate motion, because the PHS slab now follows present plate motion. However, this effect on the contraction amount is small $(\leq 1 \mathrm{~km})$, because even if the present plate motion is used, each colored line is approximately shifted to the location of the next colored line for 1 Myr (e.g., the blue line approximately moves to the location of the green line), although the strike of the lines is slightly different (less than $1^{\circ}$ ) and the location of the end points differs by about $20 \mathrm{~km}$. On the other hand, the convergence rate of the PHS plate possibly has a significant effect on the estimate of the contraction rates. As mentioned above, the spatial change in the contraction amount of the PHS slab is regarded as the temporal change of it in this study. Hence, if the plate convergence rate is $x$ times faster than the assumed rate, the estimated contraction rate becomes $x$ times larger. A comparison of Seno et al. (1993) with other plate motion models (e.g., Sella et al. 2002; Kreemer et al. 2003) shows that the plate convergence rate might be more than $10 \%$ faster.

The assumed strike of the Nankai Trough, which is simply taken by the straight gray line as shown in Figs. 2a and $3 \mathrm{a}$, also has a non-negligible effect, for example, a few degrees of change in the strike of the gray line can lead to a difference in the contraction amount of a few kilometers. Geometrical effects, caused by deformation of the colored lines on which contraction amounts are measured, also cause estimation errors. For example, as shown in Fig. 4, the horizontal length of the measured line should be shortened with the progress of contraction, but the same length is taken as the measured line in this study. However, estimation errors due to geometrical effects are relatively small, because they are principally the second order of small amounts.

In summary, the estimation of the contraction amount beneath the inland region of central Japan may include an uncertainty of several kilometers, except for the effect of the tear beneath the Kii Strait. It is not easy to provide a definitive value of this uncertainty, but a value of $20 \pm 5 \mathrm{~mm} /$ year could be used as a rough estimate for the contraction rate beneath the inland region of central Japan for the most recent 1 Myr. This corresponds to a 
strain rate of $4-7 \times 10^{-8}$ /year. However, if there is a tear beneath the Kii Strait, these estimates could decrease by about $20 \%\left(3.5-6 \times 10^{-8}\right.$ /year). The uncertainty is not so small as discussed above, but it could be significantly reduced, if the models of plate configuration and plate motion are improved.

It would be meaningful to estimate the contraction rate of the PHS slab from the viewpoint of plate subduction dynamics. As shown in Figs. 1, 2, and 3, the PHS slab is severely deformed, and thus this subduction zone differs significantly from others. Hence, it would be an important issue to clarify how the deformation of the PHS slab has occurred. However, estimation of the contraction rate of the PHS slab has another important meaning. As mentioned in the Introduction section, the contraction rate of the PHS slab could be used as a proxy for the crustal deformation rate of the overriding plate. The spatial pattern of crustal deformation estimated from historical earthquakes and active fault data (Wesnousky et al. 1982; Kaizuka and Imaizumi 1984; Shen-Tu et al. 1995) is consistent with the results of this study; the strain rate is faster in the inland region of central Japan, while it is slower in the Pacific coastal region and Shikoku. However, the strain rates of their estimates quantitatively differ from the estimate obtained in this study; their estimates for the inland region of central Japan are only around $2-2.5 \times 10^{-8}$ /year, which is slower than the estimate of this study.

In contrast, the geodetically estimated strain rates for central Japan are about 1-2 $\times 10^{-7}$ year (e.g., Nakane 1973; Hashimoto 1990; Sagiya et al. 2000), which are faster than the estimate obtained in this study. The large discrepancy between geodetically and geologically estimated strain rates has been pointed out by Kaizuka and Imaizumi (1984), which provoked Ikeda (1996) to consider the idea of a gigantic interplate earthquake before the occurrence of the 2011 Tohoku-Oki earthquake (Ikeda et al. 2012; Ikeda 2014). The result of this study certainly suggests that the geodetically estimated strain rate is an overestimation. It is likely that the discrepancy between the geodetic and geological estimates is caused by elastic compressive deformation due to the locking on the plate interface along the Japan Trench, as exemplified by Meneses-Gutierrez and Sagiya (2016). On the other hand, the result of this study also suggests that important factors have been neglected in geological estimations of strain rates, such as unrecognized active faults and inelastic deformation (Wesnousky et al. 1982; Kaizuka and Imaizumi 1984).

As previously mentioned, the spatial pattern of crustal deformation is concordant with that of the PHS slab deformation. However, observed focal mechanisms significantly differ from each other; focal mechanisms of $\mathrm{E}-\mathrm{W}$ compression are dominant in the upper crust (e.g., Townend and Zoback 2006; Terakawa and Matsu'ura
2010), while those of E-W tension are rather usual in the PHS slab (e.g., Nakamura et al. 1997; Wang et al. 2004; Shiomi et al. 2008). This contradiction is apparently enigmatic. However, without large-scale E-W contraction, it would be impossible to make the folded structure of the PHS slab (Figs. 2 and 3). As demonstrated by Shiomi et al. (2008), E-W tension earthquakes are likely to be due to the upward bending of the PHS slab. In fact, earthquakes of E-W compression are rather dominant beneath the western Kii Peninsula (Ishikawa 2001; Shiomi et al. 2008), where the downward bending of the PHS slab occurs.

The cause of large-scale E-W contraction of the PHS slab is unknown, but it is evident that E-W crustal shortening has occurred in Honshu in the recent a few Ma, as exemplified by the movement of active faults and the development of mountain ranges (e.g., Huzita 1980; Research Group for Active Faults of Japan 1991). This means that the distance between the Japan Trench and Kyushu has been shortening. Because the location of the volcanic front around the border of northeastern and central Japan has been nearly stable since the Miocene (Seno and Maruyama 1984), it is considered that the dip angle of the subducting Pacific Plate has not changed significantly. Hence, the Pacific slab has moved westward relative to Kyushu in the recent a few Ma. The PHS slab that has subducted along the Nankai Trough lies between the Pacific slab and the mantle beneath Kyushu. Therefore, if the PHS slab could have moved westward beneath Kyushu, coinciding with the westward motion of the Pacific slab, the PHS slab would not have heavily deformed. In fact, however, the PHS slab beneath Kyushu has not moved westward (at least significantly) due to some reason (i.e., the PHS slab here is anchored in the mantle), which results in large deformation of the PHS slab. It is likely that the dense PHS slab beneath Kyushu, which is considered to retreat along the Ryukyu Trench resulting in back-arc spreading to the farther south of Kyushu (e.g., Kamata and Kodama 1999), has resisted to move westward. In brief, it is considered that the westward motion of the Japan Trench and the Pacific slab causes the E-W contraction of both the PHS slab and the overriding plate.

As for the difference in the deformation between the coastal region and the inland region, mechanical coupling seems to play an important role: the effective elastic thickness is thicker in the coastal region because the PHS slab is in contact with the overriding plate, while it is thinner in the inland region because of the existence of the mantle wedge between them. This contrast in elastic thickness is considered to be the cause of much less deformation in the fore-arc region (to the south of the Median Tectonic Line, MTL) than in the inland region. The difference of shortening may also be responsible for the activity of the MTL, because the fore-arc region needs 
to move westward as a fore-arc sliver. On the other hand, it is more difficult to explain the cause of the difference of the deformation between central and western Japan. Possibly, water supplied from the deep descending Pacific slab beneath central Japan (Nakamura et al. 2008) may play an important role, because water can efficiently weaken the mechanical strength of both the PHS slab and the overriding plate (e.g., Iio et al. 2002). But it would be a future work to clarify this problem.

\section{Conclusions}

In this study, the contraction rate of the PHS slab is estimated from the plate configuration models (the CAMP and Hirose models), assuming that the configuration of the PHS slab is stationary in time in the coordinate system fixed to the overriding plate (Honshu arc). The advantage of this method consists in the simplicity of the initial configuration of the slab, that is, it is considered that the currently observed deformation of the PHS slab has been formed only after the subduction along the Nankai Trough. The estimated contraction rate is small beneath Shikoku ( $\leq 0.3 \mathrm{~mm} /$ year) and the offshore fore-arc ( $\leq 0.6 \mathrm{~mm} /$ year), except for the northernmost part of Shikoku (approximately $3 \mathrm{~mm}$ /year). On the other hand, it increases beneath central Japan from south to north; it is $3-6 \mathrm{~mm} /$ year in the Pacific coastal region and reaches $20 \pm 5 \mathrm{~mm} /$ year in the inland region, which is equivalent to the strain rate of $4-7 \times 10^{-8} /$ year. However, the strain rate beneath the inland region of central Japan could be reduced by about $20 \%\left(3.5-6 \times 10^{-8} /\right.$ year $)$, if the PHS slab has a tear beneath the Kii Strait. Because the spatial pattern of the deformation of the PHS slab corresponds well with that of the upper crust, the estimated value could be used as a proxy for crustal deformation rates, thus providing an independent estimate of the crustal deformation rate in central Japan over the long term. The estimated value, which is slower than the geodetic estimate while faster than the geologic one, could compromise the large discrepancy (about one order) between the strain rates estimated by the geodetic and the geologic methods.

\section{Abbreviations \\ CAMP: Crustal Activity Modeling Program; GMT: General Mapping Tool; GNSS: Global Navigation Satellite System; MTL: Median Tectonic Line; NA: North American; PHS: Philippine Sea}

\footnotetext{
Acknowledgements

The author thanks Chihiro Hashimoto and Fuyuki Hirose for providing the digital data of the PHS slab configuration model. Ritsuko Matsu'ura is also acknowledged for kindly providing the depth data of historical earthquakes. The author appreciates discussion with Yoshihisa lio. Comments by Yasutaka Ikeda and an anonymous reviewer contributed to improving the manuscript. The Catalog of Damaging Earthquakes in the World (http:// iisee.kenken.go.jp/utsu/index eng.html) was used in this study. Figures were created with the GMT software (Wessel and Smith 1998).
}

\section{Funding}

This study was supported by the Grant-in-Aid for Scientific Research on Innovative Areas (Kakenhi No. 26109003) from the Ministry of Education, Culture, Sports, Science and Technology (MEXT) to YF.

\section{Availability of data and materials}

This study used plate configuration data of the CAMP model (Hashimoto et al. 2004) and the Hirose model (Hirose et al. 2008a). The former is distributed by Chihiro Hashimoto at Nagoya University, Japan, for non-commercial use. The latter can be downloaded from Hirose's homepage (http://www.mri-jma.go.jp/Dep/st/member/fhirose/en/en.PlateData.html).

\section{Authors' contributions}

This study is carried out by YF. The author read and approved the final manuscript.

\section{Competing interests}

The author declares that he has no competing interests.

\section{Publisher's Note}

Springer Nature remains neutral with regard to jurisdictional claims in published maps and institutional affiliations.

Received: 14 May 2018 Accepted: 13 December 2018

Published online: 15 January 2019

\section{References}

Amano K (1991) Multiple collision tectonics of the south Fossa Magna in central Japan. Mod Geol 15:315-329

Asano Y, Hasegawa A (2004) Imaging the fault zones of the 2000 western Tottori earthquake by a new inversion method to estimate three-dimensional distribution of the scattering coefficient. J Geophys Res 109:B06306. https:// doi.org/10.1029/2003jb002761

Baba T, Tanioka Y, Cummins PR, Uhira K (2002) The slip distribution of the 1946 Nankai earthquake estimated from tsunami inversion using a new plate model. Phys Earth Planet Inter 132:59-73

Bird P (2003) An updated digital model of plate boundaries. Geochem Geophys Geosyst 4:1027. https://doi.org/10.1029/2001GC000252

Chinzei K, Koaze T (1995) Mountains in Hokkaido and Tohoku. In: Kaizuka S, Chinzei K (eds) Mountains in Japan. Iwanami Shoten, Tokyo, pp 29-78 (in Japanese)

Cummins PR, Baba T, Kodaira S, Kaneda Y (2002) The 1946 Nankai earthquake and segmentation of the Nankai Trough. Phys Earth Planet Inter 132:75-87

Doke R, Tanikawa S, Yasue K, Nakayasu A, Niizato T, Umeda K, Tanaka T (2012) Spatial patterns of initiation ages of active faulting in the Japanese Islands. Active Fault Res 37:1-15 (in Japanese with English abstract)

Gutscher M-A, Spakman W, Bijwaard H, Engdahl ER (2000) Geodynamics of flat subduction: seismicity and tomographic constraints from the Andean margin. Tectonics 19:814-833. https://doi.org/10.1029/1999tc001152

Hasegawa A, Nakajima J, Uchida N, Hirose F, Kita S, Matsuzawa T (2010) Slab structure beneath the Japanese islands and earthquake generation. J Geogr 119:109-204 (in Japanese with English abstract)

Hashima A, Sato T, Sato H, Asao K, Furuya H, Yamamoto S, Kameo K, Miyauchi T, Ito T, Tsumura N, Kaneda $\mathrm{H}$ (2016) Simulation of tectonic evolution of the Kanto Basin of Japan since 1 Ma due to subduction of the Pacific and Philippine Sea plates and the collision of the Izu-Bonin arc. Tectonophysics 679:1-14. https://doi.org/10.1016/j.tecto.2016.04.005

Hashimoto C, Fukui K, Matsu'ura M (2004) 3-D modelling of plate interfaces and numerical simulation of long-term crustal deformation in and around Japan. Pure Appl Geophys 161:2053-2068. https:/doi.org/10.1007/s00024-004-2548-8 Hashimoto M (1990) Horizontal strain rates in the Japanese islands during interseismic period deduced from geodetic surveys (part I): Honshu, Shikoku and Kyusyu. Zisin-2 43:13-26 in Japanese with English abstract

Hayes GP, Wald DJ, Johnson RL (2012) Slab1.0: a three-dimensional model of global subduction zone geometries. J Geophys Res 117:B01302. https://doi. org/10.1029/2011jb008524

Heki K, Miyazaki S (2001) Plate convergence and long-term crustal deformation in central Japan. Geophys Res Let 28:2313-2316. https://doi.org/10.1029/ 2000gl012537

Heki K, Miyazaki S, Takahashi H, Kasahara M, Kimata F, Miura S, Vasilenko NF, Ivashchenko A, An K-D (1999) The Amurian Plate motion and current plate 
kinematics in eastern Asia. J Geophys Res 104:29147-29155. https://doi.org/ 10.1029/1999jb900295

Hirose F (2018) Plate data. http://www.mri-jma.go.jp/Dep/st/member/fhirose/en/ en.PlateData.html. Accessed 1 May 2018

Hirose F, Nakajima J, Hasegawa A (2007) Three-dimensional velocity structure in southwestern Japan and configuration of the Philippine Sea slab estimated by double-difference tomography. Zisin-2 1-20:60 in Japanese with English absgtract

Hirose F, Nakajima J, Hasegawa A (2008a) Three-dimensional seismic velocity structure and configuration of the Philippine Sea slab in southwestern Japan estimated by double-difference tomography. J Geophys Res 113:B09315. https://doi.org/10.1029/2007jb005274

Hirose F, Nakajima J, Hasegawa A (2008b) Three-dimensional velocity structure and configuration of the Philippine Sea slab beneath Kanto District, central Japan, estimated by double-difference tomography. Zisin-2 60:123-138 in Japanese with English abstract

Huzita K (1980) Role of the median tectonic line in the Quaternary tectonics of the Japanese islands. Mem Geol Soc Japan 18:129-153

Ide $S$ (2010) Striations, duration, migration and tidal response in deep tremor. Nature 466:356-359. https://doi.org/10.1038/nature09251

Ide S, Shiomi K, Mochizuki K, Tonegawa T, Kimura G (2010) Split Philippine Sea plate beneath Japan. Geophys Res Let 37:L21304. https:/doi.org/10.1029/ $2010 \mathrm{~g} \mid 044585$

lio Y, Sagiya T, Kobayashi Y, Shiozaki I (2002) Water-weakened lower crust and its role in the concentrated deformation in the Japanese Islands. Earth Planet Sci Lett 203:245-253

Ikeda Y (1996) Implications of active fault study for the present-day tectonics of the Japan arc. Active Fault Res 15:93-99 (in Japanese with English abstract)

Ikeda Y (2014) Strain buildup in the Northeast Japan orogen with implications for gigantic subduction earthquakes. Episodes 37:234-245

Ikeda Y, Okada S, Tajikara M (2012) Long-term strain buildup in the Northeast Japan arc-trench system and its implications for gigantic strain release events. J Geol Soc Japan 118:294-312. https://doi.org/10.5575/geosoc.2012.0018

Imanaga I (1999) The geologic structure of the Ashigara group. Res Rep Kanagawa prefect Mus Nat Hist 3:41-56 (in Japanese with English abstract)

Ishikawa Y (2001) The shape of the Philippine Sea slab. J Geogr 110:592-601 (in Japanese with English abstract)

Kaizuka S, Imaizumi T (1984) Horizontal strain rates of the Japanese islands estimated from Quaternary fault data. Geogr Rep Tokyo Metrop Univ 19:43-65

Kamata H, Kodama K (1999) Volcanic history and tectonics of the Southwest Japan Arc. Island Arc 8:393-403

Kreemer C, Holt WE, Haines AJ (2003) An integrated global model of present-day plate motions and plate boundary deformation. Geophys I Int 154:8-34

Matsuda T (1978) Collision of the Izu-Bonin arc with central Honshu: Cenozoic tectonics of the Fossa Magna, Japan. J Phys Earth 26:S409-S421

Matsu'ura R (2017) A short history of Japanese historical seismology: past and the present. Geosci Lett 4:3. https://doi.org/10.1186/s40562-017-0069-4

Meneses-Gutierrez A, Sagiya T (2016) Persistent inelastic deformation in central Japan revealed by GPS observation before and after the Tohoku-oki earthquake. Earth Planet Sci Lett 450:366-371. https://doi.org/10.1016/j.epsl. 2016.06.055

Mizoue M, Nakamura M, Seto N, Ishiketa Y (1983) Three-layered distribution of microearthquakes in relation to focal mechanism variation in the Kii peninsula, southwestern Honshu. Japan Bull Earthq Res Inst 58:287-310

Nakajima J, Hasegawa A (2007) Subduction of the Philippine Sea plate beneath southwestern Japan: slab geometry and its relationship to arc magmatism. J Geophys Res 112. https://doi.org/10.1029/2006jb004770

Nakajima J, Hirose F, Hasegawa A (2009) Seismotectonics beneath the Tokyo metropolitan area, Japan: effect of slab-slab contact and overlap on seismicity. J Geophys Res 114:B08309. https://doi.org/10.1029/2008jb006101

Nakamura H, Iwamori H, Kimura J (2008) Geochemical evidence for enhanced fluid flux due to overlapping subducting plates. Nat Geosci 1:380-384

Nakamura M, Watanabe H, Konomi T, Kimura S, Miura K (1997) Characteristic activities of subcrustal earthquakes along the outer zone of southwest Japan. Annu Disas Prev Res Inst Kyoto Univ 40B-1:1-20 (in Japanese with English abstract)

Nakane K (1973) Horizontal tectonic strain in Japan (II). J Geod Soc Japan 19:200-208 (in Japanese with English abstract)

Okino K (1994) Evolution of the Shikoku Basin. J Geomagn Geoelectr 46:463-479

Otsubo M, Miyakawa A (2016) Landward migration of active folding based on topographic development of folds along the eastern margin of the Japan
Sea, northeast Japan. Quat Int 397:563-572. https://doi.org/10.1016/j.quaint. 2015.11.019

Ozawa S, Nishimura T, Munekane H, Suito H, Kobayashi T, Tobita M, Imakiire T (2012) Preceding, coseismic, and postseismic slips of the 2011 Tohoku earthquake, Japan. J Geophys Res 117:B07404. https://doi.org/10.1029/ 2011 jb009120

Pardo M, Suárez G (1995) Shape of the subducted Rivera and Cocos plates in southern Mexico: seismic and tectonic implications. J Geophys Res 100: 12357-12373. https://doi.org/10.1029/95jb00919

Research group for active faults of Japan (1991) Active faults in Japan. Sheet maps and inventories, revised edition. University of Tokyo Press, Tokyo

Sagiya T (2004) A decade of GEONET: 1994-2003-the continuous GPS observation in Japan and its impact on earthquake studies-. Earth Planets Space 56:29-41

Sagiya T, Miyazaki S, Tada T (2000) Continuous GPS array and present-day crustal deformation of Japan. Pure Appl Geophys 157:2303-2322

Sato H (1989) Degree of deformation of late Cenozoic strata in the Northeast Honshu Arc. Mem Geol Soc Japan 32:257-268 (in Japanese with English abstract)

Sella GF, Dixon TH, Mao A (2002) REVEL: a model for recent plate velocities from space geodesy. J Geophys Res 107. https://doi.org/10.1029/2000jb000033

Seno T, Maruyama S (1984) Paleogeographic reconstruction and origin of the Philippine Sea. Tectonophysics 102:53-84

Seno T, Stein S, Gripp AE (1993) A model for the motion of the Philippine Sea plate consistent with Nuvel-1 and geological data. J Geophys Res 98:17941-17948

Shen-Tu B, Holt WE, Haines AJ (1995) Intraplate deformation in the Japanese Islands: a kinematic study of intraplate deformation at a convergent plate margin. J Geophys Res 100:24275-24293. https://doi.org/10.1029/95jb02842

Shiomi K, Matsubara M, Ito Y, Obara K (2008) Simple relationship between seismic activity along Philippine Sea slab and geometry of oceanic Moho beneath southwest Japan. Geophys J Int 173:1018-1029. https://doi.org/10. 1111/j.1365-246X.2008.03786.X

Sugimura A (1972) Plate boundaries around Japan. Kagaku (Science) 42:192-202 (in Japanese)

Taira A (2001) Tectonic evolution of the Japanese arc system. Annu Rev Earth Planet Sci 29:109-134

Takada Y, Kobayashi T, Furuya M, Murakami M (2009) Coseismic displacement due to the 2008 Iwate-Miyagi Nairiku earthquake detected by ALOS/PALSAR: preliminary results. Earth Planets Space 61:e9-e12

Takada Y, Matsu'ura M (2004) A unified interpretation of vertical movement in Himalaya and horizontal deformation in Tibet on the basis of elastic and viscoelastic dislocation theory. Tectonophysics 383:105-131

Takahashi M (2006) Tectonic development of the Japanese islands controlled by Philippine Sea plate motion. J Geogr 115:116-123 (in Japanese with English abstract)

Takahashi M (2017) The cause of the east-west contraction of Northeast Japan. Bull Geol Surv Japan 68:155-161

Tapponnier P, Molnar P (1976) Slip-line field theory and large-scale continental tectonics. Nature 264:319-324

Terakawa T, Matsu'ura M (2010) The 3-D tectonic stress fields in and around Japan inverted from centroid moment tensor data of seismic events. Tectonics 29:TC6008. https://doi.org/10.1029/2009tc002626

Toda S, Maruyama T, Yoshimi M, Kaneda H, Awata Y, Yoshioka T, Ando R (2010) Surface rupture associated with the 2008 Iwate-Miyagi Nairiku, Japan, earthquake and its implications to the rupture process and evaluation of active faults. Zisin-2 62:153-178 (in Japanese with English abstract)

Townend J, Zoback MD (2006) Stress, strain, and mountain building in central Japan. J Geophys Res 111:B03411. https://doi.org/10.1029/2005jb003759

Ueno T, Shibutani T, Ito K (2008) Configuration of the continental Moho and Philippine Sea slab in southwest Japan derived from receiver function analysis: Relation to subcrustal earthquakes. Bull Seism Soc Am 98:2416-2427. https://doi.org/10.1785/0120080016

Utsu T (1974) Hypocenter distribution around Japan. Kagaku (Science) 44:739746 (in Japanese)

Utsu T (1990) Catalog of damaging earthquakes in the world (through 1989). Utsu, Tokuji, Tokyo

Utsu T (2002) A list of deadly earthquakes in the world: 1500-2000. In: Lee WK, Kanamori H, Jennings PC, Kisslinger C (eds) International handbook of earthquake and engineering seismology part a. Academic Press, San Diego, pp 691-717

Utsu T (2004) Catalog of damaging earthquakes in the world (through 2002), the Dbase file distributed at the memorial party of Prof. Tokuji Utsu held in 
Tokyo The revised and extended version is available at http://iisee.kenken.go. jp/utsu/index_eng.html. Accessed 1 May 2018

Wang K, Wada I, Ishikawa Y (2004) Stresses in the subducting slab beneath southwest Japan and relation with plate geometry, tectonic forces, slab dehydration, and damaging earthquakes. J Geophys Res 109:B08304. https:// doi.org/10.1029/2003jb002888

Wesnousky SG, Scholz CH, Shimazaki K (1982) Deformation of an island arc: rates of moment release and crustal shortening in intraplate Japan determined from seismicity and Quaternary fault data. J Geophys Res 87:6829-6852. https://doi.org/10.1029/JB087iB08p06829

Wessel P, Smith WHF (1998) New, improved version of generic mapping tools released. EOS Trans Am Geophys Union 79:579-579. https://doi.org/10.1029/ $98 \mathrm{EO} 00426$

Yabuki T, Matsu'ura M (1992) Geodetic data inversion using a Bayesian information criterion for spatial distribution of fault slip. Geophys J Int 109: $363-375$

\section{Submit your manuscript to a SpringerOpen ${ }^{\circ}$ journal and benefit from:}

- Convenient online submission

- Rigorous peer review

- Open access: articles freely available online

High visibility within the field

- Retaining the copyright to your article

Submit your next manuscript at $\boldsymbol{\nabla}$ springeropen.com 